\title{
Hiri-hondakinen balorizazioa digestio anaerobioaren bidez
}

(Valorization of municipal solid wastes by anaerobic digestion)

\author{
Iratxe Vallejo, Eva Epelde, Maite Artetxe*
}

Ingeniaritza Kimikoa Saila, Zientzia eta Teknologia Fakultatea (UPV/EHU)

LABURPENA: Urtez urte mundu-mailan ekoizturiko hiri-hondakin solidoen (HHS) kantitatea handituz doa. Beraz, gaur egun hiri-hondakinen kudeaketa egokia gizartearen erronka nagusietarikoa da. Halaber, erregai fosilen erabilerak ingurumenean eragindako kalteak nabarmenak dira. Horrez gaiz, jakina da energia-iturri hau agortzen ari dela. Digestio anaerobioa (DA) hiri-hondakinak kudeatzeko erabiltzen den metodoa da, eta energia berriztagarri gisa hartzen da; izan ere, hiri-hondakinetatik energia-iturria (biogasa) ekoizten da. Lan honetan, hiri-hondakinen zati organikoaren balioztapenerako DAren metodoa aztertuko da. Lehendabizi, hondakin solidoen arazoa eta haiek balioztatzeko aukera desberdinak aztertuko dira. Ondoren, DAren oinarriak zehaztuko dira, eta udal-hondakinen DA prozesuko lau etapak aztertu. Amaitzeko, operazio-baldintzek eta digestio-sistema desberdinek duten eragina aztertuko da.

HITZ GAKOAK: Digestio anaerobioa, hiri-hondakin solidoak, biogasa, kudeaketa-metodoak.

ABSTRACT: The amount of municipal solid wastes (MSWs) is annually increasing worldwide. Therefore, a suitable municipal solid waste management is one of the main concerns of our society. Furthermore, the environmental problems derived from the use of fossil fuels are outstanding, together with the depletion of this energy source. Anaerobic digestion $(A D)$ is one of the most promising management methods, which is considered as a rewenable energy source, as energy (biogas) is produced after treating the MSWs. In this work we analyse the AD method for the valorization of the organic fraction of MSWs. First, the problematic of solid wastes and different ways for their management are reported. Secondly, the basis of $A D$ are established, which consists of four steps. Finally, the effect of operating conditions and the different digestion systems are analysed.

KEYWORDS: Anaerobic digestion, municipal solid wastes, biogas, management methods.

\footnotetext{
* Harremanetan jartzeko / Corresponding author: Maite Artetxe. Ingeniaritza Kimikoa Saila, Zientzia eta Teknologia Fakultatea, Euskal Herriko Unibertsitatea (UPV/EHU), Posta-kutxa 644 (E48080 Bilbao). - maite.artetxe@ehu.eus - https://orcid. org/0000-0002-2378-216X.

Nola aipatu / How to cite: Vallejo, Iratxe; Epelde, Eva; Artetxe, Maite (2020). «Hiri-hondakinen balorizazioa digestio anaerobioaren bidez»; Ekaia, 38, 2020, 259-273. (https://doi.org/10.1387/ekaia.21849).

Jasoa: 26 ekaina, 2020; Onartua: 20 uztaila, 2020.

ISSN 0214-9001 - eISSN 2444-3255 / (c) 2020 UPV/EHU
}

cc)(i) () Obra hau Creative Commons Atribución 4.0 Internacional-en lizentziapean dago 


\section{SARRERA}

Urtero milioika hondakin tona ekoizten dira munduan zehar, batez ere udal, industria eta nekazaritza arloetatik eratorriak. Ekoiztutako hondakinen metaketaren ondorioz ingurumenean eragindako arazoek gizartearen kezka piztu dute; izan ere, hondakin organikoen deskonposizioak lurraren, airearen eta uraren kutsadura eragiten du. Halaber, urbanizazio azkarra, industrializazioa eta biztanleriaren hazkuntza dela eta, hiri-hondakin solidoen ekoizpena handitzea espero da [1]. Hau da, hiri-hondakin solidoen ekoizpen-tasa 2025. urterako 2.200 milioi tona urteko izatea espero da, eta 2050. urterako, berriz, 4.200 milioi tona urteko [2].

Europako Batzordea (EB) Ekonomiaren Lankidetza eta Garapenerako Antolakundeak (ELGA) hiri-hondakinei emandako definizioan oinarritzen da haiek sailkatzeko. ELGAren arabera, hiri-hondakinak udalerriek edo udalerrientzat bildutako edo tratatutako hondakinak dira. Izaerari dagokionez, hiri-hondakinak bost taldetan sailkatzen dira: biodegradagarriak, birziklagarriak, inerteak, konposatuak eta etxeko hondakin arriskutsuak [3].

Hondakinen areagotzeak izugarrizko eragina izan du osasunarekin lotutako arazoetan, hondakinen kudeaketan eta garraio azpiegituretan, besteak beste [4]. Alde batetik, hiri-hondakinek eulien, intsektuen, bakterioen, onddoen eta beste mikroorganismoen agerpena bultzatzen dute, eta, beraz, osasun publikoarentzat mehatxu larria dira [3]. Bestalde, hiri-hondakinen degradaziotik eratorritako lixibatuak uraren, lurzoruaren eta atmosferaren kutsadura eragiten du. Lixibatua hiri-hondakin solidoen degradazioan gertatutako aldaketa fisiko, kimiko eta biologikoen ondorioz sortzen den produktua da [5]. Oro har, lixibatuek $\mathrm{pH}$, nitrogeno amoniko eta metal astunen kontzentrazio altuak izan ohi dituzte [6]. Prezipitazioetako urak, zabortegietako hondakinetatik zehar pasatzen den neurrian, lixibatuen konposatu organikoak eta inorganikoak biltzen ditu. Kutsatutako ur hori lurzoruan zehar iragazten da, eta lurzorua bera eta haren barneko ur-kanalak kutsatzen ditu [7].

Hondakinen ekoizpenaren hazkuntzak ingurumenean eragiten dituen arazoak ikusita, hondakinen kudeaketa ingurunearen eta gizartearen osasuna zaintzeko beharrezko jarduera bilakatu da [3]. Hala ere, zoritxarrez, hiri-hondakin solidoak kudeatzeko erabiltzen diren ohiko metodoek (zabortegien erabilerak, konpostajeak eta errausketak) zenbait arazo dituzte [8]. Esate baterako, errausketara bideratzen diren hondakinek edo zabortegietan botatzen direnek metano-isuri larriak eragiten dituzte. Aipatzekoa da metanoa karbono dioxidoa baino 23 aldiz indartsuagoa den berotegi-efektu gasa dela, eta, beraz, izugarrizko eragina duela planetaren batez besteko tenperatura-aldaketan [1].

Europar Batasunak hondakinen kudeaketaren inguruan sortutako lege eta politika berriek Europako ekonomia lineala ekonomia zirkular bihurtzea 
dute helburutzat, hondakinen ekoizpena murrizteko eta azken horien birziklapena sustatzeko [9]. Ekonomia zirkularra material gordinen eta hondakinen ekoizpena murriztea helburutzat duen estrategia da. Europar parlamentuaren arabera, ekonomia zirkularra produkzio- eta kontsumo-eredu bat da, lehendik dauden materialak eta produktuak partekatu, alokatu, berrerabili, konpondu, berritu eta birziklatzea ahalbidetzen duena, horrela balio erantsia sortzeko. Modu horretan, produktuen bizitza-zikloa luzatu egiten da. Hondakinen hierarkia Europar Batasunak hondakinak kudeatzeko ezarri duen eredua da. Hondakinen kudeaketa-aukeren aurrean lehentasunordena ezartzen du, eta kudeaketa-estrategiek ingurumenean izan ditzaketen eraginak kontuan hartzen ditu. 1. irudian ikusten denez, Europak ezarritako kudeaketa-ereduak hondakinen bazterketa baino gehiago, hondakinak murriztea, birziklatzea eta berrerabiltzea bultzatzen du [10], eta, beraz, $3 \mathrm{R}$ (reduce, recycle, reuse) legean oinarritzen dela ondoriozta daiteke. Aipatzekoa da, nahiz eta $3 \mathrm{R}$ barruan ez sartu, hondakinen hierarkiak birziklapenaren eta bazterketaren artean berreskurapena ere kontsideratzen duela.

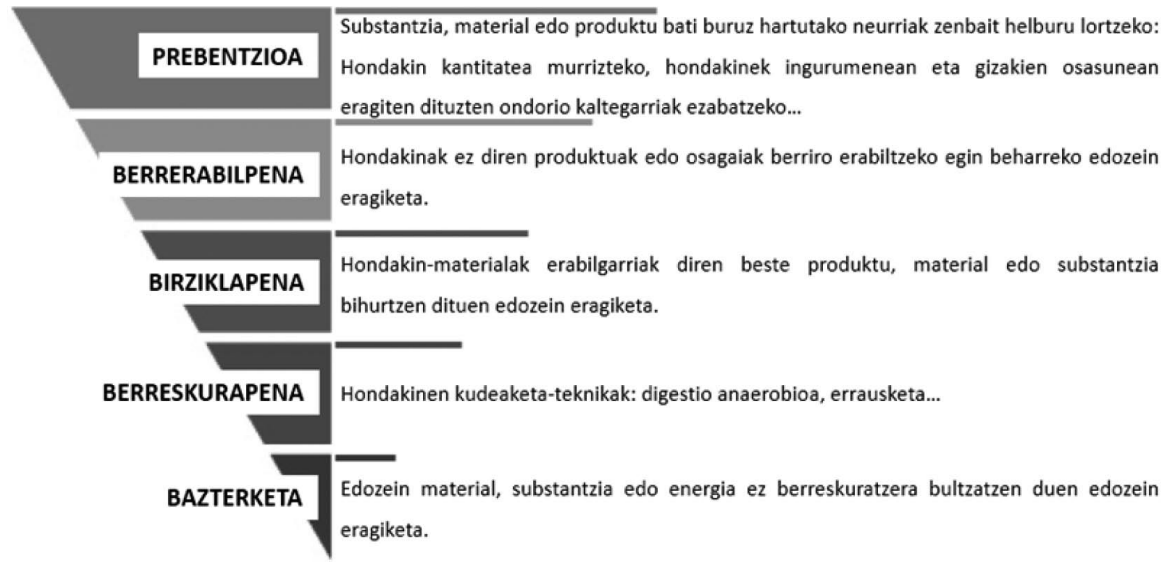

1. irudia. Europako batzordeak ezarritako hondakinen hierarkia [10].

Eurostaten arabera, 2000-2014 urteetan zehar, hiri-hondakin solidoen tratamenduan aldaketa nabaria izan da [8]. Horrela, zabortegietara isuritako hondakin kopurua $288 \mathrm{~kg}$-tik $131 \mathrm{~kg} /$ pertsona-ra jaitsi da. Aipatu beharra dago hiri-hondakin solidoen \%27,8 birziklapen (konpostatzea, materialen birziklatzea eta digestio anaerobioa kontuan izanda) bidez tratatzen dela. Horrela, hiri-hondakinen errausketaren aurretik kokatu da birziklapena.

Hiri-hondakinak tratatzeko metodo desberdinen artean, digestio anaerobioa (DA) hondakin organikoen kudeaketarako teknologia egokitzat hartzen da, alde batetik hondakinen egungo kudeaketak eragindako ingurumen arazoak murrizten dituelako, eta, bestetik, energia-iturri berriztagarria delako. 
Aipatu beharra dago hiri-hondakinen frakzio organikoa soilik trata daitekeela metodo horren bidez. DA mikroorganismoen presentzian gertatzen den materia organikoaren degradazioa da. DAren bidez tratatutako hondakin organikoa biogasa eta digestatu bilakatzen da, zeinak energia-iturri eta ongarri moduan erabilgarriak diren, hurrenez hurren. Beraz, prozesuan zehar ekoiztutako biogasa erregai fosilen ordezko moduan erabil daiteke. Horrez gain, DAk ez du eragin negatiborik ez gizakien osasunean, ez eta ingurumenean ere [11]. Horrela, hiri-hondakin solidoen kudeaketan eta energia-iturri berriztagarrien arloan geroz eta gehiago ikertzen den teknologia bilakatu da DA [12].

\section{DIGESTIO ANAEROBIOAREN OINARRIAK}

Digestio anaerobioa mikroorganismoen bidez eta baldintza anaerobioetan gertatzen den prozesua da, non karbono organikoa oxidazio-erredukzio erreakzioen bidez $\mathrm{CO}_{2}$ eta $\mathrm{CH}_{4}$ bihurtzen den [13]. DAren produktuak biogasa $\left(\% 60-70 \mathrm{CH}_{4}\right.$, $\%$ 30-40 $\mathrm{CO}_{2}$ eta ezpurutasunak) eta hondakin organikoa dira [14].

Prozesua lau fasetan banatzen da (2. irudia): hidrolisia, azidogenesia (hartzidura), azetogenesia, eta metanogenesia [15]. Fase bakoitzean gertatzen diren erreakzioak aurrera eramaten dituzten mikroorganismoek ezaugarri desberdinak dituzte: fisiologia, elikadura-beharrak, hazkuntza-zinetika eta ingurumenarekiko sentikortasuna, besteak beste [16].

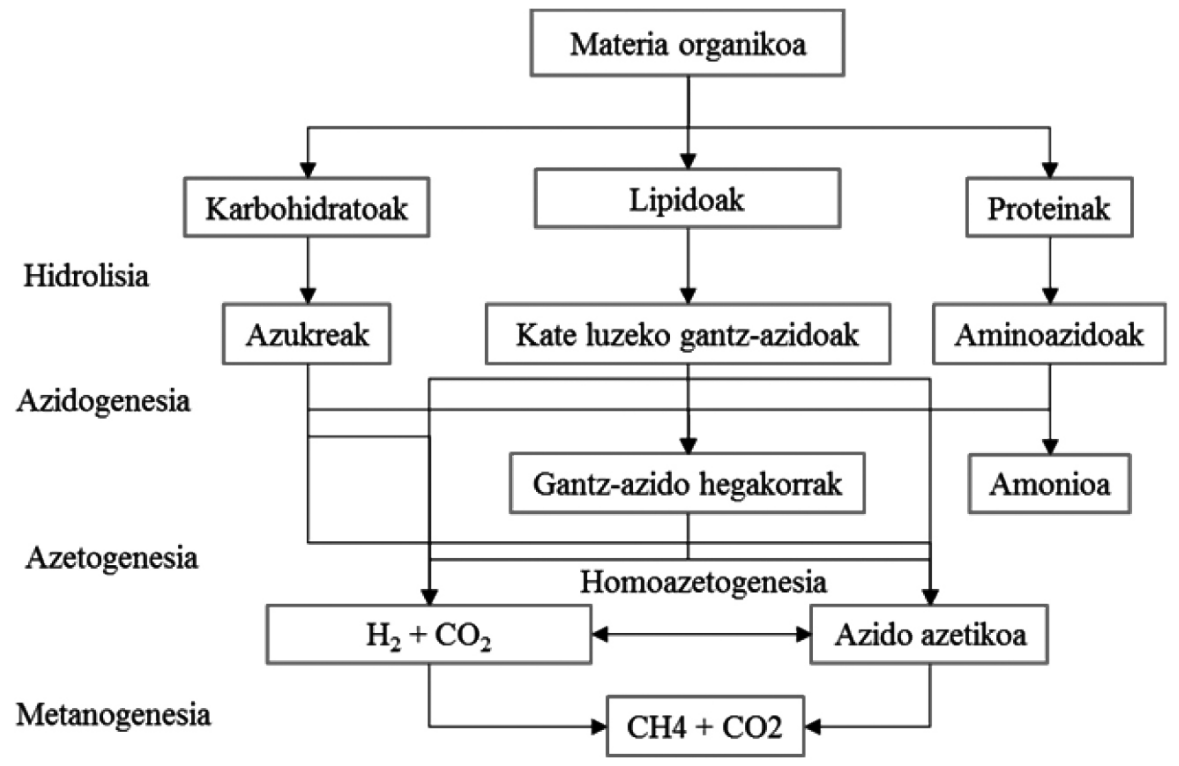

2. irudia. Digestio anaerobioaren lau faseak eta horien ondorioz ekoizten diren produktuak [15]. 
DAren lehenengo urratsari hidrolisia deritzo, non hiri-hondakinen parte diren pisu molekular handiko osagai organikoak (lipidoak, karbohidratoak eta proteinak, besteak beste) pisu molekular txikiagoa duten osagai (gantzazido, glukos eta aminoazido) bilakatzen diren, mikroorganismoek jariatzen dituzten entzimen bitartez [17].

$$
\left(\mathrm{C}_{6} \mathrm{H}_{10} \mathrm{O}_{5}\right)_{\mathrm{n}}+\mathrm{nH}_{2} \mathrm{O} \rightarrow \mathrm{nC}_{6} \mathrm{H}_{12} \mathrm{O}_{6}
$$

Digestore anaerobioetan tratatzen den biomasak, sarritan, mikroorganismoentzako eskuraezinak diren osagaiak izan ohi ditu. Zelulosa molekulak, adibidez, hidrolisiaren bitartez molekula txikiagotan apurtzen dira (1. ekuazioa), ondoren bakterio azidogenikoentzat erabilgarriak izan daitezen [18]. Mikroorganismo hidrolitikoek ingurumen-baldintza aldakorrei eta erabilitako substratuan egon daitezkeen toxinei aurre egiteko gaitasuna dute [17]. Oro har, hidrolisi-etaparen tenperatura optimoa $30-50{ }^{\circ} \mathrm{C}$-koa da, eta $\mathrm{pH}$ balio optimoak 5-7 tartekoak dira [18].

Behin hidrolisi-fasean ekoiztutako monomeroak zelulen barruan sartzen direnean, mikroorganismo azidogenikoak gai dira gantz-azido lurrunkorrak (azido azetikoa, azido propionikoa, azido butirikoa, eta abar) eta beste zenbait produktu ekoizteko [18]: besteak beste, alkoholak, hidrogenoa eta karbono dioxidoa [16].

$$
\begin{aligned}
& \mathrm{nC}_{6} \mathrm{H}_{12} \mathrm{O}_{6} \rightarrow 3 \mathrm{n} \mathrm{CH}_{3} \mathrm{COOH} \\
& \mathrm{C}_{6} \mathrm{H}_{12} \mathrm{O}_{6}+2 \mathrm{H}_{2} \rightarrow 2 \mathrm{CH}_{3} \mathrm{CH}_{2} \mathrm{COO}^{-}+2 \mathrm{H}^{+}+2 \mathrm{H}_{2} \mathrm{O} \\
& \mathrm{C}_{6} \mathrm{H}_{12} \mathrm{O}_{6} \rightarrow \mathrm{CH}_{3}\left(\mathrm{CH}_{2}\right)_{2} \mathrm{COO}^{-}+\mathrm{H}^{+}+2 \mathrm{CO}^{2}+2 \mathrm{H}_{2} \\
& \mathrm{C}_{6} \mathrm{H}_{12} \mathrm{O}_{6} \rightarrow 2 \mathrm{CH}_{2} \mathrm{CH}_{2} \mathrm{OH}+2 \mathrm{CO}_{2}
\end{aligned}
$$

Azidogenesi-fasean gertatzen diren glukosaren erreakzioak 2-5. ekuazioetan adierazten dira [17]. Fase honetan eratzen den azidorik garrantzitsuena $\mathrm{CH}_{3} \mathrm{COOH}$ da; izan ere, $\mathrm{CH}_{4}$ ekoizten duten mikroorganismoek azido hori substratu modura erabiltzen dute [11]. pH-balioek nabarmen eragiten dute gantz-azido lurrunkorren ekoizpenean, eta azidogenesiaren pH-balio optimoa 5,5-6,5 tartean optimizatua dago, haien ekoizpena maximizatzeko asmoz [17].

Aurrez aipatu den moduan, digestio anaerobioaren aurreko fasean azido azetikoa $\left(\mathrm{CH}_{3} \mathrm{COOH}\right)$ ekoizten den arren, azidogenesi-fasean ekoiztutako gantz-azido lurrunkorrak oraindik ez daude mikroorganismo metanogenikoentzat eskuragarri [18]. Hori dela eta, azetogenesi-fasean, azidogenesian zehar sortutako eta zuzenean metanoa ekoizteko erabil ezin daitezkeen produktuak mikroorganismo metanogenikoek erabil ditzaketen substratu bihurtzen dira [16]. 


$$
\begin{aligned}
& \mathrm{CH}_{3} \mathrm{CH}_{2} \mathrm{COO}^{-}+2 \mathrm{H}_{2} \mathrm{O} \rightarrow \mathrm{CH}_{3} \mathrm{COO}^{-}+\mathrm{CO}_{2}+3 \mathrm{H}_{2} \\
& \mathrm{CH}_{3}\left(\mathrm{CH}_{2}\right)_{2} \mathrm{COO}^{-}+2 \mathrm{H}_{2} \mathrm{O} \rightarrow 2 \mathrm{CH}_{3} \mathrm{COO}^{-}+\mathrm{H}^{+}+2 \mathrm{H}_{2} \\
& \mathrm{CH}_{3} \mathrm{CH}_{2} \mathrm{OH}+\mathrm{H}_{2} \mathrm{O} \rightarrow \mathrm{CH}_{3} \mathrm{COO}^{-}+\mathrm{H}^{+}+2 \mathrm{H}_{2} \\
& 2 \mathrm{CO}_{2}+4 \mathrm{H}_{2} \rightarrow \mathrm{CH}_{3} \mathrm{COO}^{-}+\mathrm{H}^{+}+2 \mathrm{H}_{2} \mathrm{O}
\end{aligned}
$$

Beraz, azetogenesian, azidogenesian ekoiztutako gantz-azido lurrunkorrak azido azetiko, hidrogeno eta karbono dioxido bihurtzen dira, 6-9. ekuazioetan adierazten den moduan [17]. Azetogenesian ekoiztutako hidrogenoak mikroorganismo azetogenikoen aktibitatea inhibitzen du. Hala ere, metanoa ekoizten duten mikroorganismoen presentzia dela eta, ekoiztutako hidrogenoa azkar kontsumitzen da [18]. Modu honetan, bai bakterio azetogenikoentzat zein metanogenikoentzat beharrezkoa den sinbiosia sortzen da [11]. Mikroorganismo azetogenikoen pH-balio optimoa 6,0-6,2 bitartekoa da [17].

Metanoa oinarrizko bi mekanismoren bitartez ekoizten da: metanogenesi azetoklastikoaren edo metanogenesi hidrogenotrofoaren bitartez.

$$
\begin{aligned}
& \mathrm{CH}_{3} \mathrm{COOH} \rightarrow \mathrm{CH}_{4}+\mathrm{CO}_{2} \\
& \mathrm{CO}_{2}+4 \mathrm{H}_{2} \rightarrow \mathrm{CH}_{4}+2 \mathrm{H}_{2} \mathrm{O}
\end{aligned}
$$

Metanogenesi azetoklastikoaren kasuan, bakterio azetotrofoek azido azetikoa metano eta karbono dioxido bihurtzen dute hartziduraren bitartez (10. ekuazioa). Metanogenesi hidrogenotrofoaren kasuan, aldiz, bakterio metanogeno hidrogenotrofoek substratu gisa karbono dioxidoa eta hidrogenoa erabiltzen dute metanoa ekoizteko, 11. ekuazioan adierazten den moduan [17]. Oro har, metanogenesi azetoklastikoaren bitartez sorturiko metano totalaren bi heren ekoizten dira, eta gainerakoa metanogenesi hidrogenotrofikoaren bitartez ekoizten da [18].

Metanoa ekoizten duten mikroorganismoei mikroorganismo metanogenikoak deritze. Aipatzekoa da mikroorganismo hauek oxigeno kantitate txikien presentzian beren aktibitatea galtzen dutela. Mikroorganismo metanogenoen artean aipagarrienak honako hauek dira: Methanobrevibacter ruminantium, M. bryantic eta M. thermoautotrophicum, besteak beste [11].

\section{DIGESTIO ANAEROBIOAREN DISEINU-PARAMETROAK}

Digestio anaerobioan eragina duten aldagai nagusiak honako hauek dira: (1) Tenperatura, (2) pHa, (3) Karbono/nitrogeno erlazioa $(\mathrm{C} / \mathrm{N})$, (4) Karga organikoaren tasa (KOT) eta (5) Erretentzio-denbora (ED). 
Tenperatura DAn eragiten duen aldagai kritikoa da. Digestio anaerobioan erabiltzen den tenperatura prozesuan parte hartzen duten mikroorganismoek tenperaturarekiko duten tolerantziaren araberakoa da [19]. Digestio anaerobioko prozesuetan bi tenperatura-erregimen nagusi erabiltzen dira [18]: mesofiloa, 30-40 ${ }^{\circ} \mathrm{C}$-tan eta termofiloa, 50-60 ${ }^{\circ} \mathrm{C}$-tan [20]. Mikroorganismo mesofiloek tenperatura baxuagotan lan egiten dutenez, erreakzioak motelagoak dira eta biogas kantitate txikiagoa ekoizten da. Hala ere, erregimen mesofiloan lan egiten duten sistemak termofiloak baino erakargarriagoak izan ohi dira; izan ere, sistema berotzeko energia gutxiago kontsumitzen dute [18]. Erregimen termofiloan lan egiten duten sistemek, tenperatura altuagotan lan egiten dute; hortaz, hiri-hondakinen deskonposizio-prozesua azkarrago gertatzen da, eta, beraz, denbora gutxiago behar da biogas kantitate altuagoa lortzeko [21]. Gainera, tenperatura altuek sisteman edo elikadura fluxuan egon daitezkeen patogenoak suntsi ditzakete [18]. Hala ere, aipatzekoa da DA erregimen termofiloan egitean azidifikazioa gerta litekeela eta horrek biogasaren produkzioa inhibi dezakeela [22]. Azidifikazioan gantz-azido lurrunkorren ekoizpen altua gertatzen da. Horrek digestorearen pHa aldatzen du, mikroorganismoaren baldintza optimoetatik aldenduz eta biogasaren produkzioa jaitsiz.

Bestalde, DA prozesuan erabiltzen den $\mathrm{pH}$-balioak bai prozesuan bai ekoizturiko produktuetan eragiten du. DAn erabiltzen diren $\mathrm{pH}$,balioak 6,87,4 tartekoak dira [22]; izan ere, $\mathrm{pH}$ tarte horretan mikroorganismoak aktiboak dira, eta aurrera eramaten den digestio prozesua eraginkorra da [14]. Aipatzekoa da, DAren hasierako fasean gantz-azido lurrunkorren sorrerak pHaren balioa jaisten duen arren, sistemak normalean neutraltasuna mantentzeko gaitasuna duela. Izan ere, gantz-azido lurrunkorrez gain, $\mathrm{CO}_{2} \mathrm{a}$ ere sortzen da, eta horrek hidroxido ioiekin erreakzionatzen du, eta $\mathrm{HCO}_{3}{ }^{-}$sortu eta horrela digestorearen neutraltasuna mantendu [21]. Hala ere, ekoizten den azidoen kontzentrazioa oso altua denean, digestorearen barruko $\mathrm{pH}-$ balioak behera egiten du, eta horrek hartzidura-prozesua inhibitzen du [20].

Horrez gain, hiri-hondakinetan ageri den nitrogeno kantitatea biogasa ekoizteko berebiziko garrantzia duen faktorea da; izan ere, karbonoarekin batera, nitrogenoa funtsezko osagaia da mikroorganismoak hazteko eta ugaltzeko [14]. $\mathrm{C} / \mathrm{N}$ erlazioak digestiorako erabili den substratuan ageri den mantenugai-maila islatzen du; hori dela eta, digestio-sistemak $\mathrm{C} / \mathrm{N}$ erlazioarekiko sentikorrak dira [22]. $\mathrm{C} / \mathrm{N}$ erlazio baxua duten substratuek amoniakoaren bidezko inhibizioa jasotzen dute. Izan ere, $\mathrm{C} / \mathrm{N}$ erlazio desegokiak amoniakoa eta gantz-azido lurrunkorrak aska ditzake. Bai amoniakoa bai eta gantz-azido lurrunkorrak ere digestio anaerobioaren inhibitzaileak dira; izan ere, mikroorganismo metanogenikoen jarduera gutxitzen dute [14]. C/N erlazio altuetan, berriz, zelularen biomasa mantentzeko beharrezkoa den nitrogeno kantitatea ez da nahikoa izaten [22]. Horren ondorioz, mikroorganismoen populazioak txikiak izango dira, eta 
denbora luzeagoa beharko dute eskuragarri dagoen karbonoa deskonposatzeko [21]. Hiri-hondakinetan nitrogeno kantitate baxua izatea gerta liteke; beraz, hori handitzeko gehigarritzat simaurra edo urea gehigarriak erabil daitezke [20]. Digestio anaerobioan erabiltzen diren $\mathrm{C} / \mathrm{N}$ ratio optimoak 20-30 edo 30-35 balioen artekoak dira: oro har, gehien erabiltzen den balioa 25 da [22].

Karga organikoaren tasa (KOT) egunero digestorearen bolumen unitateko elikatzen den materia organikoaren kantitateari deritzo [14]. Digestorearen bolumenaren, elikadura kontzentrazioaren, erretentzio-denbora hidraulikoaren eta $\mathrm{C} / \mathrm{N}$ erlazioaren araberakoa da KOT [20]. KOT zenbat eta altuagoa izan, areagotu egiten da biogasaren etekina neurri batean; hala ere, aldi berean, digestio-prozesuaren oreka eta produktibitatea kaltetua suerta daitezke. Egunero digestorera material berrien bolumen handi bat gehitzeak aldaketak sor ditzake hango ingurumen-balditzetan. Aldaketa horiek bakterioen jardueran eragin dezakete, besteak beste hartziduraren hasierako fasea erabat inhibituz. Bakterioen inhibizioa KOT balio altuen ondorioz gertatzen da. Izan ere, bai bakterio hidrolitikoen bai bakterio azidogenikoen jarduera areagotzen dute, eta, beraz, gantz-azido lurrunkorren kontzentrazioak gora egiten du [22].

Materia organikoak biogas bilakatzeko digestorearen barruan igarotzen duen denborari erretentzio-denbora deritzo. Erretentzio-denbora DA prozesuaren tenperaturaren, KOTren eta erabilitako substratuaren araberakoa da, eta, gainera, mikroorganismoen hazkuntza-tasarekin erlazionatuta dago [22]. Erretentzio-denbora ez da 2-4 egun baino baxuagoa izaten [14].

\section{DIGESTIO ANAEROBIOAREN DISEINUA}

Gaur egun, hondakin organikoen digestio anaerobioa gero eta gehiago aztertzen ari da, baliabideen berreskurapena eta hondakinen egonkortasuna eskaintzen dituen teknologia garatzen saiatzeko [12]. Digestio anaerobioaren sistemarik sinpleena erreaktore bakarraz osatutako sistema da, non prozesuaren lau urratsak ematen diren. Horri etapa bakarreko digestio-sistema deritzo. Hala ere, zientziaren eta bioteknologiaren garapenarekin batera, digestio-urrats bakoitzak operazio-baldintza optimo desberdinak dituela ikusi da. Hori dela eta, digestio-urratsen banaketa fisikoaren ideia biltzen duen sistema (etapa anitzeko digestio-sistema) garatu da, digestio-fase bakoitzaren etekin altuena lortzeko asmoz [10]. Europan funtzionamenduan ageri diren instalazioen \% 90ek gutxigora behera hiri-hondakinen zati organikoaren digestio anaerobioa fase bakarreko sistemaren bitartez egiten du. Horren arrazoi nagusia da etapa bakarreko sistemen diseinua bi etapa edo etapa anitzeko sistemen diseinua baino sinpleagoa eta ekonomikoagoa dela [12]. 
Etapa bakarreko digestio-sistema batean, digestio anaerobioan parte hartzen duten mikroorganismo guztiak bolumen berean daude, eta ingurumen-baldintzak ez dira optimoak izango bakterio jakin bakoitzerako, baizik eta bakterio guztientzat izango dira onargarriak [23]. Etapa bakarreko digestio-sistemek honako baldintza hauetan lan egiten dute: substratuen $\mathrm{C} / \mathrm{N}$ balioa 15-30 artean dago, pHaren balioa 6,8 eta 7,4 artean, erretentzio-denbora bakterio mesofiloentzat 30 egun da, termofiloentzat 20 egun eta sikrofiloentzat 50 egun [17]. Etapa bakarreko digestio-sistemak, bi mota desberdinetan sailkatu daitezke, sistemak duen eduki solidoaren (ESren) arabera (1. taula): hezea (ES < \% 15) eta lehorra $(\mathrm{ES}>\%$ 15) [15].

1. taulan ikusten denez, digestio-sistema hezeak bi taldetan sailkatu daitezke: hein baxuko sistemak (KOT = 0,5-1,6 $\mathrm{kg}-\mathrm{VS} / \mathrm{m}^{3} \mathrm{egun}^{-1}$ ) eta hein altuko sistemak $\left(\mathrm{KOT}=1,6-4,8 \mathrm{~kg}-\mathrm{VS} / \mathrm{m}^{3}\right.$ egun $\left.^{-1}\right)$. Hein baxuko sistema hezea da motarik zaharrena eta sinpleena. Nahiz eta sistema horren operazioa erraza izan, oso errendimendu baxua du. Bestalde, hein altuko sistema hezea hein baxuko sistematik garatu da, batez ere azken horren errendimendua hobetzeko helburuarekin.

Hein altuko sistema hezeetan, elikadura-fluxua berotu eta nahastu egin daiteke; modu horretan, ingurune uniformea lortzen da, eta, beraz, prozesua aurrera eramateko beharrezkoa den erreaktorea txikiagoa, egonkorragoa eta eraginkorragoa da [17]. Solido-kontzentrazio altuak dituzten hondakinak digestio sistema hezeen bidez trata daitezke; hala ere, hondakinei ur kantitate handia gehitu behar zaie. Hori dela eta, bai beharrezko uraren zein energia-kontsumoaren kostuak areagotu egiten dira. Halaber, hondakinen diluzioak ekoizten den biogasaren etekina murriztu egiten du. Hortaz, egoera horren aurrean, digestio-sistema lehorrak garatu dira solidokontzentrazio altuak dituzten hondakinak tratatzeko [17]. Digestio-sistema lehorretan tratatzen diren hondakinen solido-kontzentrazio altuak direla eta, beste sistema motekin konparatuz, sistema hauek manipulazio, nahasketa-teknika eta tratamendu gehigarriak behar dituzte. Sistema lehorren arazo nagusia lohien garraioa eta manipulazioa da [24].

Aurrez aipatu bezala, etapa bakar batean lan egiteaz gain etapa anitzeko sistema erabiliz lan egin daiteke. Etapa anitzeko digestio-sistemen ideiaren oinarria, digestio anaerobioaren fase desberdinen banaketa fisikoa da fase bakoitzaren errendimendua optimizatzeko helburuarekin. Gaur egun digestio anaerobioan erabiltzen diren etapa anitzeko sistemak bi edo hiru etapakoak dira. Bi etapako sistemetan bi erreaktore desberdin erabiltzen dira hidrolisi/azidogenesi faseak eta azetogenesi/metanogenesi faseak banatzeko. Azken bi etapa horiek behar dituzten propietate fisiologikoen eta nutrienteen behar desberdinak direla eta, azetogenesi eta metanogenesi faseak banatzeko saiakera egin da. Horrela, hiru etapako sistema konplexuagoak garatu dira, non hidrolisi/azidogenesi faseak, azetogenesi fasea eta metanogenesi fasea banatzen diren [17]. 
1. taula. Etapa bakarreko digestio-sistema lehorren eta hezeen arteko konparaketa [17].

\begin{tabular}{|c|c|c|c|c|}
\hline \multicolumn{2}{|c|}{$\begin{array}{c}\text { Digestio-sistema } \\
\text { mota }\end{array}$} & Abantailak & Desabantailak & Aplikazioak \\
\hline \multirow[b]{2}{*}{ Hezea } & $\begin{array}{c}\text { Hein } \\
\text { baxua }\end{array}$ & $\begin{array}{l}\text { - Operazio erraza } \\
\text { - Sistema merkeak }\end{array}$ & $\begin{array}{c}\text { - Biogas-etekin baxua } \\
\text { - Bakarrik eskala txi- } \\
\text { kian aplika daiteke }\end{array}$ & - Ongarrien ekoizpena \\
\hline & $\begin{array}{l}\text { Hein } \\
\text { altua }\end{array}$ & $\begin{array}{l}\text { - Teknologia garatua } \\
\text { - Ponpaketa erraza }\end{array}$ & $\begin{array}{l}\text { - Prozesu konplexua- } \\
\text { goa } \\
\text { - Energia-kostu han- } \\
\text { dia }\end{array}$ & $\begin{array}{l}\text { - Nekazaritza-produk- } \\
\text { tuen ekoizpena } \\
\text { - Industriatik eratorri- } \\
\text { tako uren tratamen- } \\
\text { dua }\end{array}$ \\
\hline \multicolumn{2}{|c|}{ Lehorra } & $\begin{array}{l}\text { - Jarraitua: uraren kon- } \\
\text { tsumo baxua, erreak- } \\
\text { tore-bolumen txikia, } \\
\text { hondakin-uren ekoiz- } \\
\text { pen txikia... } \\
\text { - Ez-jarraitua: merkea- } \\
\text { goa, hala ere, jarrai- } \\
\text { tua baino bolumen } \\
\text { handiagoa behar du }\end{array}$ & $\begin{array}{l}\text { - Substratuen nahas- } \\
\text { keta eta zirkulazio } \\
\text { zaila (biskositatea } \\
\text { dela eta) } \\
\text { - Osatu gabeko degra- } \\
\text { dazioa } \\
\text { - Ezin da ES baxuak } \\
\text { dituzten sistemetan } \\
\text { aplikatu }\end{array}$ & $\begin{array}{l}\text { - Jarraitua: hirigunee- } \\
\tan \\
\text { - Ez-jarraitua: landa } \\
\text { eremuetan }\end{array}$ \\
\hline
\end{tabular}

Aipatutako bi sistemek (etapa bakarreko eta anitzeko sistemek), bai modu jarraituan zein ez-jarraituan lan egin dezakete. Erreaktore jarraituetan, prozesua etenik gabe gertatzen da, konponketa- eta garbiketa-jarduerak izan ezik. Erreaktore ez-jarraituetan, berriz, prozesua gelditu egiten da tratatuko den materiala digestorean sartzeko [14]. Prozesu ez-jarraituetan, tratatuko den materiala erreaktorearen barruan sartzen da digestioprozesuaren hasieran, eta han uzten da erretentzio-denbora osoan zehar. Digestio-prozesua amaitu ondoren, erreaktorearen edukiaren zati bat edo eduki osoa digestoretik ateratzen da [23]. Erreaktore ez-jarraituek zenbait abantaila izaten dituzte; hona, besteak beste: teknologiari dagokionez nahiko sinpleak dira, mantentze-eskakizun baxuak dituzte eta kostu baxua dute [24]. Prozesu jarraituetan, berriz, tratatuko den materiala etengabe sartzen da erreaktorean eta digeritutako materialaren kantitate berdina erreaktoretik ateratzen da aldi berean [23]. Bi sistema hauez gain, digestorean modu erdi-jarraituan ere lan egin daiteke, elikadura edo produktua modu jarraituan elikatu edo jasoz. DAren kasuan, erdi-jarraituan lan egiten den kasu gehienetan, elikadura-denbora jakin batez modu jarraituan elikatzen da eta produktuak amaieran jasotzen dira [23].

Aurretik aipatutako digestore anaerobioen arteko konparaketa 2. taulan ageri da. Ikus daitekeen moduan, lorturiko biogasaren etekina bai digesto- 
reen konfigurazioaren (etapa bat edo bi) bai operazio moduaren araberakoa da (jarraitua, ez-jarraitua edo erdi-jarraitua). Horrez gain, aurrez aipaturiko lan-baldintzek (erreaktoreko pHak, tenperaturak, erretentzio-denborak eta karga organiko totalak) mugatuko dute lorturiko biogasaren etekina.

2. taula. Digestore desberdinen arteko konparaketa [17].

\begin{tabular}{|c|c|c|c|c|c|c|c|}
\hline \multicolumn{8}{|c|}{ Etapa bakarreko erreaktoreak } \\
\hline $\begin{array}{l}\text { Hondakin } \\
\text { mota }\end{array}$ & $\begin{array}{l}\text { Operazio- } \\
\text { modua }\end{array}$ & $\begin{array}{l}\mathrm{ES} \\
(\%)\end{array}$ & $\begin{array}{c}T \\
\left({ }^{\circ} \mathrm{C}\right)\end{array}$ & $\mathrm{pH}$ & $\begin{array}{l}\text { EDH } \\
\text { (Egun) }\end{array}$ & $\begin{array}{c}\text { KOT } \\
\left(\mathrm{gVS} . \text { egun }^{-1 / L}\right)\end{array}$ & Biogas-etekina \\
\hline HHSFO & Jarraitua & 1,75 & 55 & 7,94 & 25 & 1,35 & $404 \mathrm{mLCH}_{4} / \mathrm{gVS}$ \\
\hline HHSFO & Ez-jarraitua & 11,0 & 30 & $7-7,4$ & 19 & - & 314 mLBiogas/gVS \\
\hline $\mathrm{JH}$ & Jarraitua & 2,57 & 35 & 7,8 & 60 & 2,4 & $448 \mathrm{mLCH}_{4} / \mathrm{gVS}$ \\
\hline $\mathrm{JH}$ & Erdi-jarraitua & 6,8 & 35 & $6,8-7,3$ & 4,6 & 9 & $540 \mathrm{mLCH}_{4} / \mathrm{gVS}$ \\
\hline $\mathrm{JH}$ & Jarraitua & 7,2 & 37 & 7,8 & 16 & 9,2 & $455 \mathrm{mLCH}_{4} / \mathrm{gVS}$ \\
\hline \multicolumn{8}{|c|}{ Bi etapako erreaktoreak } \\
\hline $\begin{array}{l}\text { Hondakin } \\
\text { mota }\end{array}$ & $\begin{array}{l}\text { Operazio- } \\
\text { modua }\end{array}$ & $\begin{array}{l}\mathrm{ES} \\
(\%)\end{array}$ & $\begin{array}{c}T \\
\left({ }^{\circ} \mathrm{C}\right)\end{array}$ & $\mathrm{pH}$ & $\begin{array}{l}\text { EDH } \\
\text { (Egun) }\end{array}$ & $\begin{array}{c}\text { KOT } \\
\left(\mathrm{gVS} . \text { egun }^{-1 / L}\right)\end{array}$ & Biogas-etekina \\
\hline HHS & $\begin{array}{l}\text { Erdi-jarraitua } \\
\text { Jarraitua }\end{array}$ & $\begin{array}{l}3,9 \\
1,9\end{array}$ & $\begin{array}{l}37 \\
\pm 1\end{array}$ & $\begin{array}{c}5,5-6 \\
Z G\end{array}$ & $\begin{array}{l}5,5 \\
15\end{array}$ & $\begin{array}{c}9 \\
2,5\end{array}$ & $710 \mathrm{mLBiogas} / \mathrm{gVS}$ \\
\hline HHS & $\begin{array}{l}\text { Erdi-jarraitua } \\
\text { Jarraitua }\end{array}$ & $\begin{array}{l}8,2 \\
6,7\end{array}$ & $\begin{array}{l}34,6 \\
54,9\end{array}$ & $\begin{array}{l}\mathrm{ZG} \\
\mathrm{ZG}\end{array}$ & $\begin{array}{l}4,6 \\
7,7\end{array}$ & $\begin{array}{c}16,4 \\
7,4\end{array}$ & $560 \mathrm{mLBiogas} / \mathrm{gVST}$ \\
\hline $\mathrm{JH}$ & $\begin{array}{l}\text { Erdi-jarraitua } \\
\text { Erdi-jarraitua }\end{array}$ & $\begin{array}{l}11,7 \\
10,8\end{array}$ & $\begin{array}{l}55 \\
35\end{array}$ & $\begin{array}{c}5,5 \\
7,3-7,7\end{array}$ & $\begin{array}{c}1,3 \\
5\end{array}$ & $\begin{array}{l}11,2 \\
1,16\end{array}$ & $\begin{array}{l}464 \mathrm{mLCH}_{4} / \mathrm{gVS} \\
283 \mathrm{mLH}_{2} / \mathrm{gVS}\end{array}$ \\
\hline $\mathrm{JH}$ & $\begin{array}{l}\text { Jarraitua } \\
\text { Jarraitua }\end{array}$ & $\begin{array}{l}3,57 \\
3,06\end{array}$ & $\begin{array}{l}55 \\
35\end{array}$ & $\begin{array}{l}5,36 \\
7,59\end{array}$ & $\begin{array}{c}3 \\
12\end{array}$ & $\begin{array}{l}106 \\
1,24\end{array}$ & $440 \mathrm{mLCH}_{4} / \mathrm{gVS}$ \\
\hline $\mathrm{JH}$ & $\begin{array}{l}\text { Jarraitua } \\
\text { Jarraitua }\end{array}$ & $\begin{array}{l}7,91 \\
7,53\end{array}$ & $\begin{array}{l}55 \\
35\end{array}$ & $\begin{array}{l}3,61 \\
7,32\end{array}$ & $\begin{array}{c}6 \\
24\end{array}$ & $\begin{array}{c}38,4 \\
6,6\end{array}$ & $450 \mathrm{mLCH}_{4} / \mathrm{gVS}$ \\
\hline
\end{tabular}

HHSFO: Hiri-hondakin solidoen frakzio organikoa; JH: Janari-hondakinak; HHS: Hiri-hondakin solidoak: VS: Bolumen solidoa; VST: Bolumen solido totala; ES: Eduki solidoa; T: Tenperatura; EDH: Erretentzio denbora hidraulikoa; KOT: Karga organikoaren tasa.

Ekoizten den biogasaren etekinaz gain, konposizioa ere alda daiteke digestio anaerobioan erabiltzen den elikaduraren konposizioaren, prozesuaren baldintzen eta digestoreen arabera [25]. Hala ere, biogasaren batez besteko konposizioa honako hau dela esan daiteke: \% 60-65 $\mathrm{CH}_{4}, \% 35-40 \mathrm{CO}_{2}$, $\%$ 0,5-1 $\mathrm{H}_{2} \mathrm{~S}$ eta gainerakoa ur-lurruna [14]. Biogasa energia-iturri berriztagarria da; izan ere, biogasa erregai fosilen ordezko gisa erabil daiteke [26]. 
Hala ere, biogasa erabili baino lehen, purifikatu beharra dago. Biogasaren purifikazio-prozesua biogasaren osagaiak diren $\mathrm{CO}_{2}, \mathrm{H}_{2} \mathrm{~S}$ eta hidrokarburo halogenatuak, besteak beste, kentzean datza. Azken biek natura korrosiboa dute, eta karbono dioxidoak biogasak duen energia-edukia murrizten du. Hauek baztertuz lorturiko gasa, beste erregai fosiletatik eratorritakoarekin konpara liteke [27].

Garbiketa-prozesuan metodo desberdin ugari erabiltzen dira [27]. Komertzialki lau metodo erabiltzen dira $\mathrm{CO}_{2}$ a eliminatzeko: ur bidezko arazketa, polietinen glikol bidezko arazketa, karbonozko bahe molekularrak eta mintzak. Bestalde, $\mathrm{H}_{2} \mathrm{~S}$ eliminatzeko ur edo $\mathrm{NaOH}$ bidezko arazketa edo aire/oxigeno kantitate txikiak digestorera gehitzea dira garbiketa-estrategiarik erabilienak. Horrez gain, hidrokarburo halogenatuak kentzeko ikatz aktibozko presiopeko dorreak dira erabilienak.

Biogasaren ekoizpenarekin batera lortutako hondakin organikoak (digestatua), lurzoruko mantenugaiak aberasteko ongarritzat erabil daitezke [28]. Hiri-hondakin organikoaren digestio anaerobioaren ondorioz ekoizten den digestatua tratatu den biomasa-sarreren edo substratuaren araberakoa izango da, bai eta baldintza eta digestio-sistemaren konfigurazioaren araberakoa ere [29]. Aipatu beharra dago gaur egun prozesua biogasaren ekoizpena optimizatzera bideratzen dela, digestatuaren etekina eta kalitatea kontuan izan gabe. Hala ere, etorkizunean digestatua mikroalgak haztera edo bioerregai edo bioetanola ekoiztera bideratu daiteke [29].

\section{ONDORIOAK}

Gaur egungo gizartean hiri-hondakinen metaketak sortzen dituen arazoak saihesteko ezinbesteko bilakatu da kudeaketa-metodo berriak ikertzea. Horien artean, digestio anaerobioa onartu da metodo interesgarrienetarikotzat, non hiri-hondakinen zati organikoa biogas bilaka daitekeen. Horrela, hondakinek dakarten ingurumen-arazoa murrizteaz gain, erregai fosilen ordezko energia-iturri berriztagarria izan daiteke. Beraz, hondakinen kudeaketaren eta energiaren ikuspuntutik interesa duen metodoa da.

Hiri-hondakinen digestio anaerobioa lau fasetan gertatzen da: hidrolisia, azidogenesia, azetogenesia eta metanogenesia. Fase bakoitzak operazio-baldintza optimoak dituen arren, normalean etapa bakarrean burutzen den prozesua da. Hala ere, fase bakoitza eta biogasaren errendimendua optimizatzeko asmoz, etapa anitzeko sistemak erabili izan dira, gehienez hiru etapa erabiliz hidrolisi/azidogenesi, azetogenesia eta metanogenesia bananduz.

Lorturiko biogasaren errendimendua eta konposizioa, digestorearen diseinuaren menpekoa izateaz gain, tenperaturaren, $\mathrm{pH}$ balioaren, $\mathrm{C} / \mathrm{N}$ erla- 
zioaren, karga organikoaren tasaren eta erretentzio-denboraren araberakoak dira. Horrela, lorturiko errendimenduak $404-540 \mathrm{ml}_{\mathrm{CH}} / \mathrm{g}_{\text {solido }}$ artekoak izan ohi dira, eta biogasaren konposizioa \% 60-65 $\mathrm{CH}_{4}, \% 35-40 \mathrm{CO}_{2}$ eta gainerakoa ezpurutasunak izan ohi dira.

\section{BIBLIOGRAFIA}

[1] PHAM, T. P. T., KAUSHIK, R., PARSHETTI, G. K., MAHMOOD, R., BALASUBRAMANIAN, R. 2015. «Food waste-to-energy conversion technologies: Current status and future directions». Waste Management, 38, 399408.

[2] KUMAR, A., SAMADDER, S. R. 2017. «A review on technological options of waste to energy for effective management of municipal solid waste». Waste Management, 69, 407-422.

[3] ATALIA, K. R., BUHA, D. M., BHAVSAR, K. A., SHAH, N. K. 2015. «A review on composting of municipal solid waste». Journal of Environmental Sciences, 9, 20-29.

[4] ABDEL-SHAFY, H. I., MANSOUR, M. S. M. 2018. «Solid waste issue: Sources, composition, disposal, recycling, and valorization». Egyptian Journal of Petroleum, 95, 181-188.

[5] YOUCAI, Z. 2018. Leachate generation and characteristics. Pollution control technology for leachate from municipal solid waste. Butterworth-Heinemann, Oxford.

[6] RAGHAB, S. M., ABD El MEGUID, A. M., HEGAZI, H. A. 2013. «Treatment of leachate from municipal solid waste landfill». HBRC Journal, 9, 187-192.

[7] OLOLADE, O. O., MAVIMBELA, S., OKE, S. A., MAKHADI, R. 2019. «Impact of leachate from northern landfill site in bloemfontein on water and soil quality: implications for water and food security». Sustainability, 11, 4238.

[8] MATSAKAS, L., GAO, Q., JANSSON, S., ROVA, U., CHRISTAKOPOULOS, P. 2017. «Green conversion of municipal solid wastes into fuels and chemicals». Electronic Journal of Biotechnology, 26, 69-83.

[9] MALINAUSKAITE, J., JOUHARA, H., CZAJCZYŃSKA, D., STANCHEV, P., KATSOU, E., ROSTKOWSKI, P. THORNE R.J., COLÓN J., PONSÁ S., AL-MANSOUR F., ANGUILANO L., KRZYZYNSKA R., LÓPEZ I. C., VLASOPOULOS A., SPENCER, N. 2017. «Municipal solid waste management and waste-to-energy in the context of a circular economy and energy recycling in Europe». Energy, 141, 2013-2044.

[10] VAN EWIJK, S., STEGEMANN, J. A. 2014. «Limitations of the waste hierarchy for achieving absolute reductions in material throughput». Journal of Cleaner Production, 132, 122-128. 
[11] ANUKAM, A., MOHAMMADI, A., NAQVI, M., GRANSTRÖM, K. 2019. «A Review of the chemistry of anaerobic digestion: methods of accelerating and optimizing process efficiency». Processes, 7, 504.

[12] MUHAMMAD NASIR, I., MOHD GHAZI, T. I., OMAR, R. 2012. «Production of biogas from solid organic wastes through anaerobic digestion: a review». Applied Microbiology and Biotechnology, 95, 321-329.

[13] KOUGIAS, P. G., ANGELIDAKI, I. 2018. «Biogas and its opportunities: A review». Frontiers of Environmental Science \& Engineering, 12, 1-12.

[14] JAIN, S., JAIN, S., WOLF, I. T., LEE, J., TONG, Y. W. 2015. «A comprehensive review on operating parameters and different pretreatment methodologies for anaerobic digestion of municipal solid waste». Renewable \& Sustainable Energy Reviews, 52, 142-154.

[15] RABII, A., ALDIN, S., DAHMAN, Y., ELBESHBISHY, E. 2019. «A review on anaerobic co-digestion with a focus on the microbial populations and the effect of multi-stage digester configuration». Energies, 12, 1106.

[16] ADEKUNLE, K. F., OKOLIE, J. A., 2015. «A review of biochemical process of anaerobic digestion». Advances in Bioscience and Biotechnology, 6 , 205-12.

[17] VAN, D P, FUJIWARA, T, THO, B. L., TOAN, P. P. S., MINH G. H. 2019. «A review of anaerobic digestion systems for biodegradable waste: Configurations, operating parameters, and current trends». Environmental Engineering Research. 25, 1-17.

[18] MEEGODA, J., LI, B., PATEL, K., WANG, L. 2018. «A review of the processes, parameters, and optimization of anaerobic digestion». International Journal of Environmental Research and Public Health, 15, 2224.

[19] SARKER, S., LAMB, J. J., HJELME, D. R., LIEN K. M. 2019. «A Review of the role of critical parameters in the desing and operation of biogas production plants». Applied Sciences, 9, 1915.

[20] WANG, J. 2014. «Decentralized biogas technology of anaerobic digestion and farm ecosystem: opportunities and challenges». Frontiers in Energy Research, 2, 1-12.

[21] IGONI, A. H., AYOTAMUNO, M. J., EZE, C. L., OGAJI, S. O. T., PROBERT, S. D. 2008. «Designs of anaerobic digesters for producing biogas from municipal solid-waste». Applied Energy, 85, 430-438.

[22] MAO, C., FENG, Y., WANG, X., REN, G. 2015. «Review on research achievements of biogas from anaerobic digestion». Renewable \& Sustainable Energy Reviews, 45, 540-555.

[23] OSTREM, K. 2004. Greening waste: Anaerobic digestion for treating the organic fraction of municipal solid wastes. Doktorego Tesia, New York: Columbia Univ.

[24] KOTHARI, R., PANDEY, A. K., KUMAR, S., TYAGI, V. V., TYAGI, S. K. 2014. «Different aspects of dry anaerobic digestion for bio-energy: An overview». Renewable \& Sustainable Energy Reviews, 39, 174-195. 
[25] KUO, J., DOW, J. 2017. «Biogas production from anaerobic digestion of food waste and relevant air quality implications». Journal of the Air \& Waste Management Association, 67, 1000-1011.

[26] SÁRVÁRI, H. I., TABATABAEI, M., KARIMI, K., KUMAR, R. 2016. «Recent updates on biogas production - a review». Biofuel Research Journal, 10, 394-402.

[27] KOSHTA, V., PATEL, H. R., CHAUDHARI, A. R., SHAH, B.P., PATEL, B.M. 2019. «Use of biogas as energy source: A review». International Journal of Current Microbiology and Applied Sciences, 8, 1540-1547.

[28] MIR, M. A., HUSSAIN, A.,VERMA, C. 2016. «Design considerations and operational performance of anaerobic digester: A review». Cogent Engineering, 3, 1-20.

[29] LOGAN, M., VISVANATHAN, C. 2019. «Management strategies for anaerobic digestate of organic fraction of municipal solid waste: Current status and future prospects». Waste Management Research, 37, 27-39. 